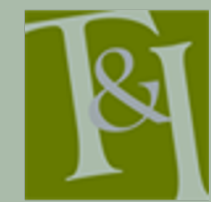

The International Journal for Translation \& Interpreting Research trans-int.org

\section{Open access in translation studies: A bibliometric overview of its distribution and development}

\author{
Javier Franco Aixelá \\ University of Alicante, Spain \\ Javier.Franco@gcloud.ua.es \\ Christian Olalla-Soler \\ MC2 Lab, Università di Bologna, Italy \\ christian.olalla@unibo.it \\ Sara Rovira-Esteva \\ Universitat Autònoma de Barcelona, Spain \\ Sara.rovira@uab.cat
}

DOI: 10.12807/ti.113201.2021.a01

\begin{abstract}
This article provides an analysis of open access (OA) publishing in translation studies for the 1961-2015 period. To this end, we have taken advantage of the translation-studies (TS) bibliographical database BITRA, which comprised over 75,000 entries as of December 2018, over 21,000 of which had been labelled as OA. The main bibliometric factors we examined from both synchronic and diachronic perspectives were the global status of OA, publication format, language, topic, kind of publisher and types of websites hosting OA publications, while also providing an estimation of how these factors predict OA. The results indicate that we are increasingly witnessing a balance between open and toll access due to the dramatic growth of OA in TS. We have also found that $\mathrm{OA}$ is still on the increase in TS, although with some notable variations within each of the categories under analysis.
\end{abstract}

Keywords: open access; translation studies; bibliometrics; publishing practices

\section{Introduction}

A spectre is haunting academia - the spectre of Open Access (OA). Promoters of free access to science are working hard towards a goal that for the first time in history seems feasible in terms of both availability and cost. More and more governments demand publicly funded research to be disseminated in OA. Commercial publishers try to adapt to the times and argue that the rigorous dissemination of science can hardly be provided by freelancers and part-time publishers without the necessary funds and know-how, while declaring their own willingness to provide open-access science - at a cost. Reckless adventurers under the guise of predatory journals take advantage of anxiousto-publish academics and provide unfiltered science, also for a profit. However, as far as we know, the debate about the advantages and drawbacks of open access within Translation Studies (TS) has not started yet. The only work we are aware of in this respect is the volume edited by García González

Translation \& Interpreting Vol. 13 No. 1 (2021) 
and Sandrini (2015), which is basically a call for more OA in TS. There is also the work by Desblache (2012), who argues that OA TS journals can be helpful in combatting the invisibility of the discipline. As evidenced by Plan $\mathrm{S}^{1}$, the state of things is changing rapidly, and it is difficult to know to what extent these winds of change are affecting our discipline. Open access is a complex phenomenon which urgently needs to be examined from a historical and bibliometric point of view. In this article, we will try to make a start with this through a detailed analysis of the development and distribution of OA in TS.

Despite the fact that, according to UNESCO $(2015$, p. 5), the first open access (OA) peer-reviewed journal dates back to as early as 1990, the widespread use of the concept as we understand it nowadays appeared more recently, in 2002, when the Open Society Institute launched the Budapest Open Access Initiative (BOAI). Since then, a series of declarations and manifestos, such as the Bethesda Statement on Open Access Publishing and the Berlin Declaration on Open Access to Knowledge in the Sciences and Humanities, both in 2003, have been drafted and published in order to expand the scope of OA and promote its adoption worldwide. Swan (2012, p. 18) considers that "these three (Budapest, Bethesda and Berlin), often used together and referred to as the 'BBB definition of Open Access', have become established as the working definition".

For reasons of space, we will neither review all the existing definitions of OA nor go into detail about its different technical and legal aspects. A working definition satisfying the needs of the present study would be that of the Budapest Open Access Initiative (BOAI) (Chan et al., 2002) which defined academic $\mathrm{OA}$ as:

[...] free availability on the public internet, permitting any users to read, download, copy, distribute, print, search, or link to the full texts of these articles, crawl them for indexing, pass them as data to software, or use them for any other lawful purpose, without financial, legal, or technical barriers other than those inseparable from gaining access to the internet itself. The only constraint on reproduction and distribution, and the only role for copyright in this domain, should be to give authors control over the integrity of their work and the right to be properly acknowledged and cited.

We borrow Swan's (2012, p. 11) words to list the multiple and various benefits provided by OA:

[...] improves the speed, efficiency and efficacy of research, is an enabling factor in interdisciplinary research, enables computation upon the research literature, increases the visibility, usage and impact of research, allows the professional, practitioner and business communities, and the interested public, to benefit from research.

In sum, providing universal access to information without bias or barriers of any kind is not only "an encouraging trend for free flow of information in the scientific worlds" but also "ensures true democratization of knowledge"

\footnotetext{
${ }^{1}$ With initiatives like Plan S (calling for publishing in fully OA journals only) launched by Science Europe in September 2018, "[w]ith effect from 2021, all scholarly publications on the results from research funded by public or private grants provided by national, regional and international research councils and funding bodies, must be published in Open Access Journals, on Open Access Platforms, or made immediately available through Open Access Repositories without embargo" (European Science Foundation, 2020).
} 
(UNESCO, 2015, p. 13) and has, therefore, an ethical dimension that must not be neglected.

As pointed out by Björk (2016, p. 131), over the past two decades, the advocacy of OA has inspired the actions of many stakeholders involved in this process. This includes academics who have founded OA journals, publishers who have started OA journals using innovative business models, librarians who have launched repositories for housing OA copies of article manuscripts, and research funders and policymakers who have defined mandates requiring open access to the results of largely publicly funded research.

Altogether this has promoted the spread of OA awareness and advocacy all over the world and has contributed to increasing the panoply of OA modes. Lately, the concept of OA, as opposed to TA (toll access), is becoming more and more complex and should be understood as a gradation rather than a dichotomy, as the following list of routes to OA illustrates:

- Diamond or Platinum OA: The publication is available OA from the very beginning and directly from the publisher, at no cost either for readers or authors.

- Gold OA: As with Diamond OA, the publication is available OA from the very beginning and directly from the publisher but authors have to pay the so-called APCs (article processing charges) to have their essays published. In the literature, diamond $\mathrm{OA}$ is seldom considered as a possibility before 2015, and even now it is usual to mention gold OA as a synonym of full open access, acting as if APCs were collateral or even ignoring them as not pertinent to the OA debate.

- Hybrid OA (mainly referring to journals): applies when the paywall model is maintained, but authors are given the choice to make their paper gold OA immediately after publication by paying APCs.

- Delayed OA: when after an embargo period the publisher either completely removes access restrictions on its own website or allows the author to self-archive a copy of the publication in different possible versions.

- Gratis, public or bronze OA: is used when documents are free-to-read from the publisher, but do not have an OA license; for example, when they are complimentary articles for the interested reader as a commercial strategy but could be made TA at any time.

- Libre OA: applies when both price barriers and permission barriers are removed.

- Green OA: refers to publications available through legal selfarchiving by the authors in personal websites, institutional repositories, academic social networks, scholarly societies or government agencies.

- Black OA, Robin Hood OA or rogue OA: have been coined for contributions "that infringe on copyrights by making them accessible to the public despite licenses that restrict them to being behind pay walls" (Archambault et al., 2014), via self-archiving to academic social media, such as Research Gate and Academia.edu, or pirate copy websites such as Sci-Hub.

From the above definitions we should realize that the concept of OA is dynamic, since the same document can belong simultaneously to more than one category or change from one to another in its lifetime. Quite often, scholarly documents that were initially not OA may, in the mid or long run, become freely available in several ways, such as delayed or gratis OA, green 
OA via self-archiving on personal websites or institutional repositories, or black OA by breaching the paywall.

Although " $[t]$ he primary, and original, target for Open Access was the journal literature (including peer-reviewed conference proceedings)" (Swan, 2012, p. 10), our study comprises other bibliographic scholarly outputs common in TS, including doctoral theses, books and book chapters. In this regard, the enthusiasm with which authors of $\mathrm{PhD}$ theses have embraced OA is noteworthy. However, as other scholars have already noted, Open Access is notoriously difficult to measure and analyses often need to resort to random sampling techniques (Melero et al., 2017). This is mainly due to two reasons: firstly, the lack of standardized tools and measurement methods to study the degree of openness in scholarly journal publishing, and secondly, the lack of a clear and consistent way to identify open access publications in bibliographic data (van Leeuwen et al., 2018). The dynamic nature of OA publications is an added dimension/difficulty.

Scholars willing to meet the OA mandate or simply to reach as many peers as possible to increase their impact in terms of citation counts have started posting their publications online, be it on their personal webpages, institutional repositories or academic social networks. A lack of awareness of publishers' embargo conditions and copyright restrictions has led to the paradox that scholars either do not share manuscript's versions they are legally entitled to or share versions of their papers that violate copyright or embargo restrictions. Moreover, attempts to accurately determine the year that a journal moved from toll access to open access, or whether a given output has become OA over time, are far from straightforward.

In sum, since the discipline of Translation Studies does not have a thematic repository, it is very difficult to arrive at an exact number of OA publications dealing with TS, especially in the case of green and bronze OA. In the OA database BITRA (Bibliography of Interpreting and Translation), with over 21,000 entries detected as OA, all the above-mentioned modes are included as OA with the only exception of publications to be found in platforms focused on black OA, because their illegal status means that access can be blocked at any moment. To our knowledge, BITRA is the only holistic TS database or repertoire including this kind of information, so that it has not been possible to compare the data with that from other sources.

The slogan "publish or perish" reflects the great pressure scholars nowadays have to face to succeed in their academic careers. However, this pressure does not only involve making their research results available to other scholars through academic publishing, but even more so to publish in journals that are considered to be of the highest quality according to their relative ranking in "international" impact indexes. Lately, the pressure has increased even more through the OA mandate, since the target publishers should satisfy this double condition, i.e., to be both open-access and high-impact journals. This notably narrows down the possibilities, especially in younger and smaller disciplines as compared with fields such as linguistics or literary studies, featuring thousands of journals worldwide. According to RETI's (2019) data, results in the case of TS cannot be more discouraging. If we understand high impact as being ranked within the first two quartiles (Q1-Q2) of Clarivate Analytics' Journal Citation Reports (JCR) there are no OA TS journals ${ }^{2}$ matching this double condition. In JCR Linguistica Antverpiensia is the only

\footnotetext{
${ }^{2}$ For a journal to be labelled as TS in BITRA, at least $50 \%$ of its articles must deal with TS. Thus, they are all highly specialized journals.
} 
journal that comes close to both requirements, and it was placed in Q4 as of 2018. If we include Scopus-based Scimago Journal Rank (SJR), the other international prestigious bibliographical ranking, out of the 147 OA active TS journals we are aware of, only nine (13\%) are found in Q1-Q2, namely, MonTI, New Voices in Translation Studies, Translation \& Interpreting (Q1), Hermeneus, Hermes, The Interpreter's Newsletter, Linguistica Antverpiensia, Panace@ and Sendebar (Q2) (RETI, 2019).

Another aspect that we need to be aware of is that almost all active TS open-access journals (96 out of 99) are edited by academics and translators working in professional associations or university departments. Therefore, these journals are generally supported by public funds, professional fees or sheer philanthropy. This means that most of them can only afford, in terms of money and human resources, issuing one or a maximum of two volumes per year. Moreover, some of these journals only publish under specific calls (such as MonTI or Linguistica Antverpiensia) or are limited in scope, such as The Interpreter's Newletter or Panace@). All these factors have resulted in a situation where demand exceeds supply, bringing about a bottleneck effect on prestigious OA journals.

The need for new venues to absorb the growing demand has given birth to both new journals (not always based on sustainable projects that can guarantee their continuity) and old commercial ones changing their business models to make them compatible with the OA requirements mandated by funders. The consequence is that authors are more and more frequently required to pay APCs if they want their papers to be gold OA. Although APC is not yet widespread, lately it has started to be a frequent occurrence in the case of TS subscription journals owned by big commercial publishers. Nowadays, the cost of publishing an article in such journals can range between 700 and $2200 €$. This can bring about the paradox of offering free science to readers which is simultaneously inaccessible for authors, many of whom cannot afford the publishing fees. Even belonging to an affluent university system can still be a problem, especially for younger researchers, if they are required to pay $2000 €$ per each article they wish to publish OA. An additional undesirable collateral effect of this emerging business model we need to be aware of is the irruption of the so-called predatory journals. Predatory journals offer questionable quick -if any- peer review and immediate publishing on the web without an embargo period, charging relatively low APCs. Although still not a too worrying phenomenon in terms of quantity, their focus on short-term profits and low-quality standards can easily deceive TS scholars anxious to publish if not alerted against them. Most worrying of all, this might cast a shadow of suspicion on $\mathrm{OA}$ as a whole, thus ruining the efforts of many serious researchers who promote OA for ideological and ethical reasons.

\section{Objectives}

This article aims to achieve a better understanding of OA in TS by providing a comprehensive picture of the conditions in which TS research is published as regards accessibility. The two main items we will address here are the global situation of the OA/TA dichotomy and its relation to factors that can potentially affect it, as well as the evolution of accessibility in TS.

In this connection, we will try to answer the following five research questions, always within TS: 
1. What is the current situation regarding OA/TA?

2. Has the situation significantly changed in the last 20 years, and can any trends be identified?

3. Which bibliometric factors among the ones we are able to examine (format, research topic, language and kind of publisher) exert a significant influence on the decision or the mere possibility of publishing OA or through TA?

4. On what kind of websites are OA documents hosted?

5. Would it be possible to quantify the degree to which all these factors act as predictors of OA or TA?

\section{Data and methods}

\subsection{From BITRA to a comprehensive ad-hoc database for the analysis of access types in Translation Studies}

A copy of the BITRA database was created on the $29^{\text {th }}$ of December 2018 and exported as a txt file. At that time, it contained 75,106 documents. A derived database for this article was then created using Excel and transferred to SPSS (v. 20) to check the consistency of the data and start the cleaning process.

The SPSS database contained an identification code for each document, the author(s) name(s), the year of publication, the title, place of publication, publisher, the type of publisher in the case of journal articles within TS journals (commercial or public), the access type (open or toll access), the language(s) of the document, the document format(s), the research topic(s) of the document, the URL to the document in the case of open access publications, and the number of citations accrued. For the present study, the number of citations was not analysed, since this will be discussed in another article which will be devoted to the impact of access type on citation counts. The final version of the database (1961-2015) contained 69,551 documents (92.6\% of BITRA), 19,067 (27.4\%) of which were available OA.

In order to work with a homogeneous sample, a period of analysis ranging from 1961 to 2015 was established and documents published before 1961 (2047 documents) and after 2015 (3508 documents) were deleted from the database. ${ }^{3}$ Since OA was virtually unheard of before 1993, when the World Wide Web became public, we decided to divide this period of analysis in two sub-periods: documents published from 1961 to 1995 (the pre-WWW period) and documents published from 1996 to 2015 (the WWW period, using the same starting year as Archambault et al., 2014). Given that the 1996-2015 period is rather broad, and that this could affect the data analysis, it was further divided into four five-year periods to better observe any possible changes or trends: 1996-2000, 2001-2005, 2006-2010 and 2011-2015.

The categories used to describe the document formats were: book, book chapter (in an edited volume), journal article, journal special issue, TS journal and $\mathrm{PhD}$ thesis. Documents sometimes were assigned to more than one category (for instance, a few $\mathrm{PhD}$ theses that have also been published as books under exactly the same title). Thus, in a few cases, a single document could have more than one format category. In the case of TS journals, the type

\footnotetext{
${ }^{3}$ Since the cited half life in Translation Studies averages around six years, the cut-off point could not be established in 2018 because it was too near to the present. Taking 2015 as an endpoint ensured that at least first citation could be detected. Moreover, although BITRA prioritises reference mining for more recent publications, the nearer the year, the less possibilities there are for citations to be detected and included.
} 
of publisher was categorised as commercial (private publishers) or public (public universities, public institutes, research and professional associations and, generally speaking, non-profit organizations).

Similarly, documents could also be assigned to more than one language. For example, some documents have been translated into several languages, whereas edited books or journal special issues occasionally contain chapters or articles in different languages. Thus, a single document could also be assigned to more than one language category. The database contained documents in 66 different languages. Since managing so many languages would have complicated the analysis procedure and the presentation of the results, only the 10 most frequent languages were selected for analysis. These languages were: English (34,565 documents), Spanish (13,478), French (8780), German (5908), Portuguese (2279), Italian (2131), Chinese (1068), Catalan (1027), Galician (402), and Polish (324). The 10 most frequent languages jointly represented $96.7 \%$ of the database.

Research topics are typically numerous within the same book and journal special issues. Even in individual journal articles or book chapters, subject combinations are much more frequent than isolated topics. In BITRA, there is a closed list of around 100 keywords to thematically describe each document. Given the diversity of keywords, the ten most frequent research topics were once again identified and selected for analysis. The research topics included were: literary translation (17,793 documents), history (9262), training (8987), scientific and technical translation (8407), interpreting (7278), professional issues (5801), machine and computer-assisted translation (4441), audiovisual translation (4427), legal translation (3190), and religious translation (2926).

URLs to the OA documents were firstly classified into seven categories: 1) public journal website (OA document which is hosted on a public journal website); 2) commercial journal website (OA document which is hosted on a commercial journal website); 3 ) institutional repository (OA document hosted on the repository of institutional entities, such as universities, research centres or public libraries); 4) private repository (OA document hosted on a repository which is not associated with an institutional entity regardless of whether the access is free or paid, such as ResearchGate, Academia.edu, Figshare, etc.); 5 ) public publisher website (OA document hosted on an institutional publisher website); 6) commercial publisher website (OA document hosted on a commercial publisher website); 7) personal website (OA document hosted on a researcher's or research group's website). Each URL was manually classified into one of these categories. In all, 16,664 URLs were classified (comprising $87.7 \%$ of all URLs pertaining to OA documents included in BITRA for the 1961-2015 period). While the categorisation process was performed manually, in some cases it was possible to automatise some processes by grouping URLs. All in all, 2336 (2.3\%) of URLs remained to be manually checked to categorize them. Given the amount of time this would require, it was decided to select a random sample of 50 URLs and to classify them into the above-mentioned categories in order to determine whether not including them would distort the results obtained with the 16,664 analysed URLs. No relevant discrepancies were found between the two sets of data.

\subsection{Data analysis}

The analysis was divided in two parts which were repeated for each analysis factor (the distribution of OA and TA in general, by format, by research topic, by language, and by journal publisher type). In the first level of analysis, the ratios of OA and TA were computed for the whole period of analysis (1961- 
2015), for the pre-WWW period (1961-1995), and for the WWW period (1996-2015). The distribution of OA and TA was compared for each factor in the 1961-2015 period, and also in the 1996-2015 period. The chi-squared test was used for this purpose given that all the data were categorical. While the data from the types of hosting of OA documents were also categorical, they were not distributed in different, independent groups that could be compared (as in the case of the OA-TA comparison). Hence, no significance tests were employed for these data. The data of the pre-WWW period was described for mainly informational purposes, since the comparison between OA and TA is not meaningful for a period when OA was not even possible, implying that all the OA documents from this period were re-issued in this mode on an unknown date, years after their original publication and, thus, really reflect current trends. The results of the first level of analysis are presented in tables.

In the second level of analysis, the diachronic evolution of OA and TA was described both in general and for each factor of analysis in four five-year periods (1996-2000, 2001-2005, 2006-2010 and 2011-2015). No statistical procedures were employed for this level of analysis, as this was not relevant for the aims of our study. The results are presented in two figures for each factor of analysis: the first shows the OA results and the second those of TA.

In another level of analysis, we carried out a binomial logistic regression (Pardo \& Ruiz, 2012) to analyse what formats, research topics, languages, and publisher types were more likely to predict OA in Translation Studies. Binomial logistic regression is a procedure used to predict the probability of obtaining one of two possible categories (in this case, OA or TA) based on specific factors (in this case, format, research topic, language, and publisher type). This procedure allowed us to identify what factors currently predict OA in Translation Studies and which ones predict TA.

\section{Results and discussion}

\subsection{Open access vs. toll access: A global and diachronic view}

As shown in Table 1, in our whole period of study (1961-2015), over one out of four documents $(27.4 \%)$ have been published OA $\left(\chi^{2}[1]=14,191.4, p<\right.$ $0.001, W=0.452$ ). Exactly $15 \%$ of the documents published in the pre-WWW period have later been re-issued in open access $\left(\chi^{2}[1]=8995.6, p<0.001, W\right.$ $=0.701)$. This shows that in the last few years there has been a remarkable trend to re-publish via open access many documents that used to be out of print or non-accessible. More and more public or non-profit initiatives and journals are now making these pre-internet documents available $\mathrm{OA}$ in a process which can only be cumulative. The difference between the two access types is less pronounced in the second period from 1996 to 2015, with $31.9 \%$ of OA $\left(\chi^{2}[1]=6738.6, p<0.001, W=0.363\right)$. Generally speaking, this ratio situates TS in line with the average of OA for academic documents, which Swan (2012) places around $30 \%$ of current publications.

Table 1. Open access vs. toll access

\begin{tabular}{ccc} 
& OA (\%) & TA (\%) \\
\hline All years & 27.4 & 72.6 \\
& $(\mathrm{n}=19,067)$ & $(\mathrm{n}=50,484)$ \\
$1961-1995$ & 15.0 & 85.0 \\
& $(\mathrm{n}=2740)$ & $(\mathrm{n}=15,576)$ \\
$1996-2015$ & 31.9 & 68.1 \\
& $(\mathrm{n}=16,327)$ & $(\mathrm{n}=34,908)$ \\
\hline
\end{tabular}


The percentage of documents published OA features a steady increase as time goes on, involving the consequent decrease in the case of documents published through TA $\left(\chi^{2}[3]=2386.8, p<0.001, V=0.216\right)$. In the 20112015 period, the number of $\mathrm{OA}$ and TA publications $(46.6 \%$ and $53.4 \%$ respectively) was already very close. Assuming this trend is to continue in the future, this may indicate that both access types could reach a balance in the forthcoming years and that OA might even overtake TA. As we will see, this has already happened in some formats. An interesting milestone in this regard is the behaviour of TS journals which started publication in the $21^{\text {st }}$ century, with $72.6 \%$ (82 out of 113 ) publishing OA since their inception.

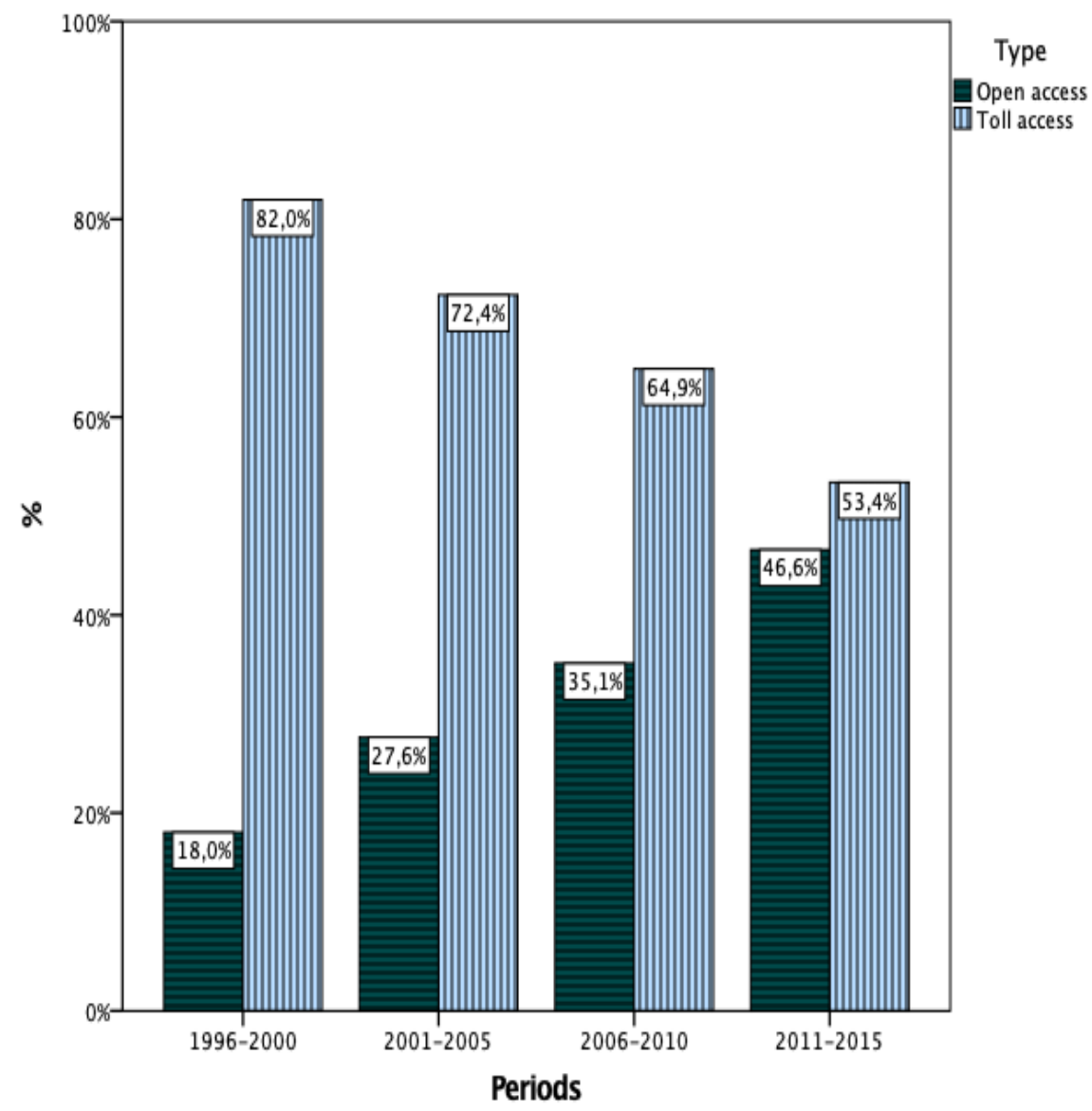

Figure 1. Diachrony of OA vs TA (1996-2015)

\subsection{The evolution of access by format}

TS books (i.e., both monographs and edited volumes) are the least frequent publication type to be published OA in the whole period of study, followed by book chapters (Table 2).

Although the percentage of journal articles that have been published OA is similar to the percentage of articles published through TA $\left(\chi^{2}[1]=186.4, p\right.$ $<0.001, W=0.078$ ), the difference is statistically significant. No difference is found when comparing journal special issues available through OA or TA $\left(\chi^{2}\right.$ $[1]=2.9, p=0.087, W=0.065)$ and also in the case of $\mathrm{PhD}$ theses $\left(\chi^{2}[1]=\right.$ $2.9, p=0.086, W=0.031)$. There are slightly more journals published OA, but the difference is not significant $\left(\chi^{2}[1]=0.9, p=0.336, W=0.066\right)$. 
Table 2. Access by format

\begin{tabular}{|c|c|c|c|c|c|c|}
\hline & \multicolumn{2}{|c|}{ All years } & \multicolumn{2}{|c|}{ 1961-1995 } & \multicolumn{2}{|c|}{$1996-2015$} \\
\hline & OA (\%) & TA (\%) & OA (\%) & TA (\%) & OA (\%) & TA (\%) \\
\hline $\begin{array}{l}\text { Journal } \\
\text { special issue }\end{array}$ & $\begin{array}{c}53.3 \\
(n=368)\end{array}$ & $\begin{array}{c}46.7 \\
(n=323)\end{array}$ & $\begin{array}{c}46.1 \\
(n=65)\end{array}$ & $\begin{array}{c}53.9 \\
(n=76)\end{array}$ & $\begin{array}{c}55.1 \\
(n=303)\end{array}$ & $\begin{array}{c}44.9 \\
(n=247)\end{array}$ \\
\hline Thesis & $\begin{array}{c}51.6 \\
(n=1575)\end{array}$ & $\begin{array}{c}48.4 \\
(n=1480)\end{array}$ & $\begin{array}{c}21.5 \\
(n=105)\end{array}$ & $\begin{array}{c}78.5 \\
(n=383)\end{array}$ & $\begin{array}{c}57.3 \\
(n=1470)\end{array}$ & $\begin{array}{c}42.7 \\
(n=1097)\end{array}$ \\
\hline $\begin{array}{l}\text { Journal } \\
\text { article }\end{array}$ & $\begin{array}{c}46.1 \\
(n= \\
13,946)\end{array}$ & $\begin{array}{c}53.9 \\
(n= \\
16,321)\end{array}$ & $\begin{array}{c}27.1 \\
(n=2356)\end{array}$ & $\begin{array}{c}72.9 \\
(n=6327)\end{array}$ & $\begin{array}{c}53.7 \\
(n= \\
11,590)\end{array}$ & $\begin{array}{c}46.3 \\
(n=9994)\end{array}$ \\
\hline Book chapter & $\begin{array}{c}10.6 \\
(n=2849)\end{array}$ & $\begin{array}{c}89.4 \\
(n= \\
24,018)\end{array}$ & $\begin{array}{c}3.2 \\
(n=184)\end{array}$ & $\begin{array}{c}96.8 \\
(n=5496)\end{array}$ & $\begin{array}{c}12.6 \\
(n=2665)\end{array}$ & $\begin{array}{c}87.4 \\
(\mathrm{n}= \\
18,522)\end{array}$ \\
\hline Book & $\begin{array}{c}3.9 \\
(n=343)\end{array}$ & $\begin{array}{c}96.1 \\
(n=8539)\end{array}$ & $\begin{array}{c}1.1 \\
(n=38)\end{array}$ & $\begin{array}{c}98.9 \\
(n=3337)\end{array}$ & $\begin{array}{c}5.5 \\
(n=305)\end{array}$ & $\begin{array}{c}94.5 \\
(n=5202)\end{array}$ \\
\hline TS journal & $\begin{array}{c}53.3 \\
(n=113)\end{array}$ & $\begin{array}{c}46.7 \\
(n=99)\end{array}$ & $\begin{array}{c}30.8 \\
(n=24)\end{array}$ & $\begin{array}{c}69.2 \\
(n=54)\end{array}$ & $\begin{array}{c}66.4 \\
(n=89)\end{array}$ & $\begin{array}{c}33.6 \\
(n=45)\end{array}$ \\
\hline
\end{tabular}

For the 1961-1995 period, almost half of the journal special issues are currently available OA. In the other formats, TA was the most frequent access type for that same period. In the 1996-2015 period, TA was also the most frequent access type in most formats (books: $\chi^{2}[1]=4354.6, p<0.001, W=$ 0.889 ; book chapters: $\chi^{2}[1]=11,867.9, p<0.001, \mathrm{~W}=0.748$; journal articles: $\chi^{2}[1]=118.0, p<0.001, \mathrm{~W}=0.074$; journal special issues: $\chi^{2}[1]=5.7, p<$ $0.05, W=0.102$; PhD theses: $\chi^{2}[1]=54.2, p<0.001, W=0.145$ ), although in the case of journal articles, journal special issues, and $\mathrm{PhD}$ theses, both access types were balanced, especially in the case of journal articles $(\mathrm{OA}=54 \%$; TA $=46 \%$ ). In this period, TS journals are more frequently published OA than through TA $\left(\chi^{2}[1]=14.5, p<0.001, W=0.328\right)$. For a correct interpretation of this data, it is important to bear in mind that journals are classified in BITRA as OA or TA according to their status as of 2018. This means that historical journals which currently publish OA are wholly considered OA, even if in some cases they have not (yet) uploaded all the past issues which were published before the WWW was launched. The situation is the same with TA pre-WWW journals, many of which have not (yet) published their oldest issues on the internet, even in TA mode.

Figure 2 shows two clear groups of formats that present different patterns of evolution regarding access type. In the first group, $\mathrm{PhD}$ theses and journal articles are published OA more and more frequently. The trend observed in the case of journal articles is related to the increasing number of (both new and old) journals that are published OA over time. This is also related to the increase of journal special issues published OA. To illustrate this point, it might be interesting to consider the situation in Spain, a relatively peripheral country. According to Kienć (2017), in this group of countries "commercial publishers are less developed due to limited profits available". Most Spanish TS journals were born as TA print-only ventures. However, by 2012, sixteen were published OA and only three through TA (Franco Aixelá, 2012). By 2018 there were 24 active TS journals in Spain: all published by non-profit organizations and all OA. 


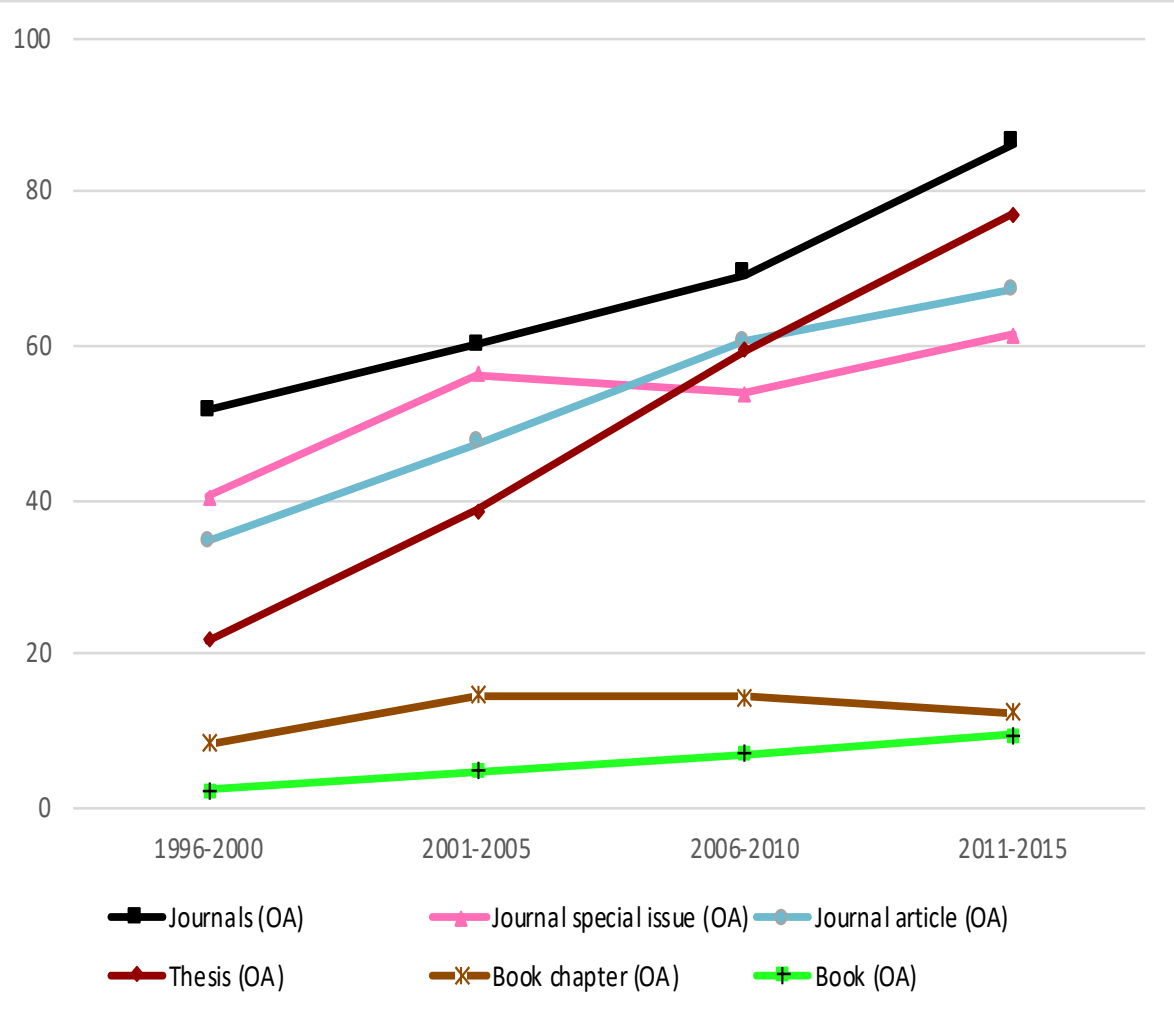

Figure 2. Evolution of access by format in percentages (1996-2015)

The very high ratio $(57.6 \%$ for $1996-2015)$ of $\mathrm{PhD}$ theses in the field of TS available OA is also noteworthy and symptomatic of the times, since it is a consequence both of university policies encouraging this mode of publication worldwide and the choice of the new generation of researchers, who more and more consider OA as the natural way of disseminating science.

In the second group, TS books and book chapters present a much lower tendency towards more frequent OA publication as time goes on. In the case of book chapters, the trend is even slightly reversed in the last period of analysis $(12.4 \%)$ compared with the third one (14.3\%). In Green's words (2017), the progress towards OA in the case of books "has been glacial." The difference regarding OA between books and chapters on the one hand, and $\mathrm{PhD}$ theses and journals on the other hand is really remarkable and needs to be explained in a specific study. In principle, there is no reason why the same universities and public institutions that publish cost-free academic journals should not publish at least the most specialized research-oriented books following the same rationale. The cost-based explanation does not seem to bear a close examination, since the publication of a journal issue is as expensive and as laborious as a book, not to mention the effort invested in a $\mathrm{PhD}$ thesis. Probably, part of the explanation has to do with tradition, i.e. with the different way books and journals are addressed in academia. Thus, books and journals seem to be managed by different agents. A university department wishing to contribute to a discipline will consider it natural to launch a journal but not a book series, leaving this format in the hands of centralized publication services. In this connection, journals have the advantage of traditionally being able to include any branch of the discipline, whereas books which are not linked to an academic conference tend to be monographic, making it more difficult to maintain a regular publication schedule. It is also 
noteworthy to include here a reference to a recent Spanish regulation (Law 14/2011, cited by Giménez Toledo, 2018, p. 21), where OA based on publicly funded research is encouraged only in journals, not even mentioning books. Also, especially in the humanities, there is still a powerful market for printed books in the form of university libraries, making these especially attractive for commercial publishers. It must be added that book processing charges, which Giménez Toledo (2018, p. 19) places around 10,000-15,000 USD, can be prohibitive, as compared with the above-mentioned APCs.

\subsection{The evolution of access by research topic}

Table 3. Access by research topic

\begin{tabular}{|c|c|c|c|c|c|c|}
\hline & \multicolumn{2}{|c|}{ All years } & \multicolumn{2}{|c|}{ 1961-1995 } & \multicolumn{2}{|c|}{$1996-2015$} \\
\hline & OA (\%) & TA (\%) & OA (\%) & TA (\%) & OA (\%) & TA (\%) \\
\hline $\begin{array}{l}\text { Machine } \\
\text { and } \\
\text { computer- } \\
\text { assisted } \\
\text { translation }\end{array}$ & $\begin{array}{l}35.2 \\
(n=1562)\end{array}$ & $\begin{array}{l}64.8 \\
(n=2879)\end{array}$ & $\begin{array}{l}20.3 \\
(n=296)\end{array}$ & $\begin{array}{l}79.7 \\
(n=1159)\end{array}$ & $\begin{array}{l}42.4 \\
(n=1266)\end{array}$ & $\begin{array}{l}57.6 \\
(n=1720)\end{array}$ \\
\hline $\begin{array}{l}\text { Scientific } \\
\text { and } \\
\text { technical } \\
\text { translation }\end{array}$ & $\begin{array}{l}34.9 \\
(n=2936)\end{array}$ & $\begin{array}{l}65.1 \\
(n=471)\end{array}$ & $\begin{array}{l}24.9 \\
(n=394)\end{array}$ & $\begin{array}{l}75.1 \\
(n=1191)\end{array}$ & $\begin{array}{l}37.3 \\
(n=2542)\end{array}$ & $\begin{array}{l}62.7 \\
(n=4280)\end{array}$ \\
\hline $\begin{array}{l}\text { Audiovisual } \\
\text { translation }\end{array}$ & $\begin{array}{l}34.7 \\
(n=1535)\end{array}$ & $\begin{array}{l}65.3 \\
(n=2892)\end{array}$ & $\begin{array}{l}10.0 \\
(n=43)\end{array}$ & $\begin{array}{l}90.0 \\
(n=389)\end{array}$ & $\begin{array}{l}37.3 \\
(n=1492)\end{array}$ & $\begin{array}{l}62.7 \\
(n=2503)\end{array}$ \\
\hline $\begin{array}{l}\text { Legal } \\
\text { translation }\end{array}$ & $\begin{array}{l}32.4 \\
(n=1032)\end{array}$ & $\begin{array}{l}67.6 \\
(n=2158)\end{array}$ & $\begin{array}{l}15.5 \\
(n=87)\end{array}$ & $\begin{array}{l}84.5 \\
(n=474)\end{array}$ & $\begin{array}{l}35.9 \\
(n=945)\end{array}$ & $\begin{array}{l}64.1 \\
(n=1684)\end{array}$ \\
\hline $\begin{array}{l}\text { Professional } \\
\text { issues }\end{array}$ & $\begin{array}{l}32.0 \\
(n=1858)\end{array}$ & $\begin{array}{l}68.0 \\
(n=3943)\end{array}$ & $\begin{array}{l}15.4 \\
(n=201)\end{array}$ & $\begin{array}{l}84.6 \\
(n=1108)\end{array}$ & $\begin{array}{l}36.9 \\
(n=1657)\end{array}$ & $\begin{array}{l}63.1 \\
(n=2835)\end{array}$ \\
\hline $\begin{array}{l}\text { Literary } \\
\text { translation }\end{array}$ & $\begin{array}{l}29.1 \\
(n=5181)\end{array}$ & $\begin{array}{l}70.9 \\
(\mathrm{n} \\
12,612)\end{array}$ & $\begin{array}{l}11.8 \\
(n=523)\end{array}$ & $\begin{array}{l}88.2 \\
(n=3921)\end{array}$ & $\begin{array}{l}34.9 \\
(n=4658)\end{array}$ & $\begin{array}{l}65.1 \\
(n=8691)\end{array}$ \\
\hline Interpreting & $\begin{array}{l}25.3 \\
(n=1841)\end{array}$ & $\begin{array}{l}74.7 \\
(n=5437)\end{array}$ & $\begin{array}{l}13.0 \\
(n=191)\end{array}$ & $\begin{array}{l}87.0 \\
(n=1282)\end{array}$ & $\begin{array}{l}28.4 \\
(n=1650)\end{array}$ & $\begin{array}{l}71.6 \\
(n=4155)\end{array}$ \\
\hline Training & $\begin{array}{l}25.3 \\
(n=2270)\end{array}$ & $\begin{array}{l}74.7 \\
(n=6717)\end{array}$ & $\begin{array}{l}10.7 \\
(n=223)\end{array}$ & $\begin{array}{l}89.3 \\
(n=1870)\end{array}$ & $\begin{array}{l}29.7 \\
(n=2047)\end{array}$ & $\begin{array}{l}70.3 \\
(n=4847)\end{array}$ \\
\hline History & $\begin{array}{l}22.8 \\
(n=2113)\end{array}$ & $\begin{array}{l}77.2 \\
(n=7149)\end{array}$ & $\begin{array}{l}11.2 \\
(n=296)\end{array}$ & $\begin{array}{l}88.8 \\
(n=2342)\end{array}$ & $\begin{array}{l}27.4 \\
(n=1817)\end{array}$ & $\begin{array}{l}72.6 \\
(n=4807)\end{array}$ \\
\hline Religion & $\begin{array}{l}17.6 \\
(n=514)\end{array}$ & $\begin{array}{l}82.4 \\
(n=2412)\end{array}$ & $\begin{array}{l}10.2 \\
(n=142)\end{array}$ & $\begin{array}{l}89.8 \\
(n=1253)\end{array}$ & $\begin{array}{l}24.3 \\
(n=372)\end{array}$ & $\begin{array}{l}75.7 \\
(n=1159)\end{array}$ \\
\hline
\end{tabular}

Even if the difference between the proportion of documents published through TA or OA for all years was statistically significant for all research topics (audiovisual translation: $\chi^{2}[1]=416.0, p<0.001, W=0.307$; machine and computer-assisted translation: $\chi^{2}[1]=390.6, p<0.001, W=0.297$; training: $\chi^{2}[1]=2200.5, p<0.001, W=0.495$; history: $\chi^{2}[1]=2738.2, p<0.001, W$ $=0.544$; interpreting: $\chi^{2}[1]=1776.8, p<0.001, W=0.494$; legal translation: $\chi^{2}[1]=397.5, p<0.001, W=0.353$; literary translation: $\chi^{2}[1]=3103.5, p<$ 
0.001, $W=0.418$; professional issues: $\chi^{2}[1]=749.4, p<0.001, W=0.359$; religion: $\chi^{2}[1]=1231.2, p<0.001, W=0.649$; scientific and technical translation: $\chi^{2}[1]=764.4, p<0.001, W=0.302$ ), they were all placed within a relatively limited range: between 20 and $35 \%$ of the documents were published OA, while 65 to $80 \%$ were published through TA (Table 3). The difference in the case of documents concerning religion was slightly more pronounced (with only $17.6 \%$ published OA), whereas in the case of documents related to machine and computer-assisted translation, the percentage of OA publications reached $35 \%$.

In the 1961-1995 period, the ratio of OA for almost all research topics ranges from 10 to $16 \%$. The percentage of documents related to machine and computer-assisted translation, and scientific and technical translation published in OA is slightly higher: $20 \%$ and $25 \%$, respectively. In the $1996-$ 2015 period, the percentage range of documents published OA is slightly larger: $24-37 \%$. Only documents related to machine and computer-assisted translation exceed that range: $42 \%$. However, the difference between the percentage of documents published OA or through TA is significant for all research topics in the WWW period comprising 1996-2015 (audiovisual translation: $\chi^{2}[1]=255.9, p<0.001, W=0.253$; machine and computerassisted translation: $\chi^{2}[1]=69.0, p<0.001, W=0.152$; training: $\chi^{2}[1]=$ 1137.2, $p<0.001, W=0.406$; history: $\chi^{2}[1]=1349.7, p<0.001, W=0.451$; interpreting: $\chi^{2}[1]=1081.0, p<0.001, W=0.432$; legal translation: $\chi^{2}[1]=$ 207.7, $p<0.001, W=0.281$; literary translation: $\chi^{2}[1]=1218.5, p<0.001, W$ $=0.302$; professional issues: $\chi^{2}[1]=308.9, p<0.001, W=0.262$; religion: $\chi^{2}$ $[1]=404.6, p<0.001, W=0.514$; scientific and technical translation: $\chi^{2}[1]=$ $442.8, p<0.001, W=0.255$ ).

Generally speaking, there seems to be an association between technical orientation and OA, perhaps due to different academic publishing behaviours within the discipline. In this connection, topics could be classified in three broad groups: firstly, publications dealing with machine, computer-assisted and technical and scientific translation, which are the most liable to be published OA (34.6\%) (see 4.6. Factors that predict open access). A second, intermediate level $(32.0 \%)$, is comprised by specialized (especially legal) translation and professional issues, whereas essays related to humanistic translation (i.e. basically literature, history and religion) are placed in the lower level (26.5\%). The difference between these three groups is statistically significant, even if the effect is small. To this hypothesis it must be added that machine and computer-assisted translation are probably one of the most difficult fields to detect for their compilation in BITRA, since it is quite frequent for them to publish conference proceedings directly on the internet, without an intermediate lodging in a journal or book. Thus, there are probably many more OA essays dealing with MT pending to be included in BITRA than with other, more traditional fields as regards their publishing behaviour.

Figure 3 shows a steady increase in the percentage of OA publications from the first (1996-2000) to the third period (2006-2010) for all research topics. This increase is more pronounced from the third to the fourth period (2011-2015) in the case of religion and translation, history, legal translation, and literary translation. In the case of audiovisual, scientific and technical translation, interpreting, training, and professional issues, the increase in the last period is less marked than in the previous ones. Machine and computerassisted translation is the research topic that is most frequently published OA, although the increase from the third to the fourth period is one of the least marked ones. 


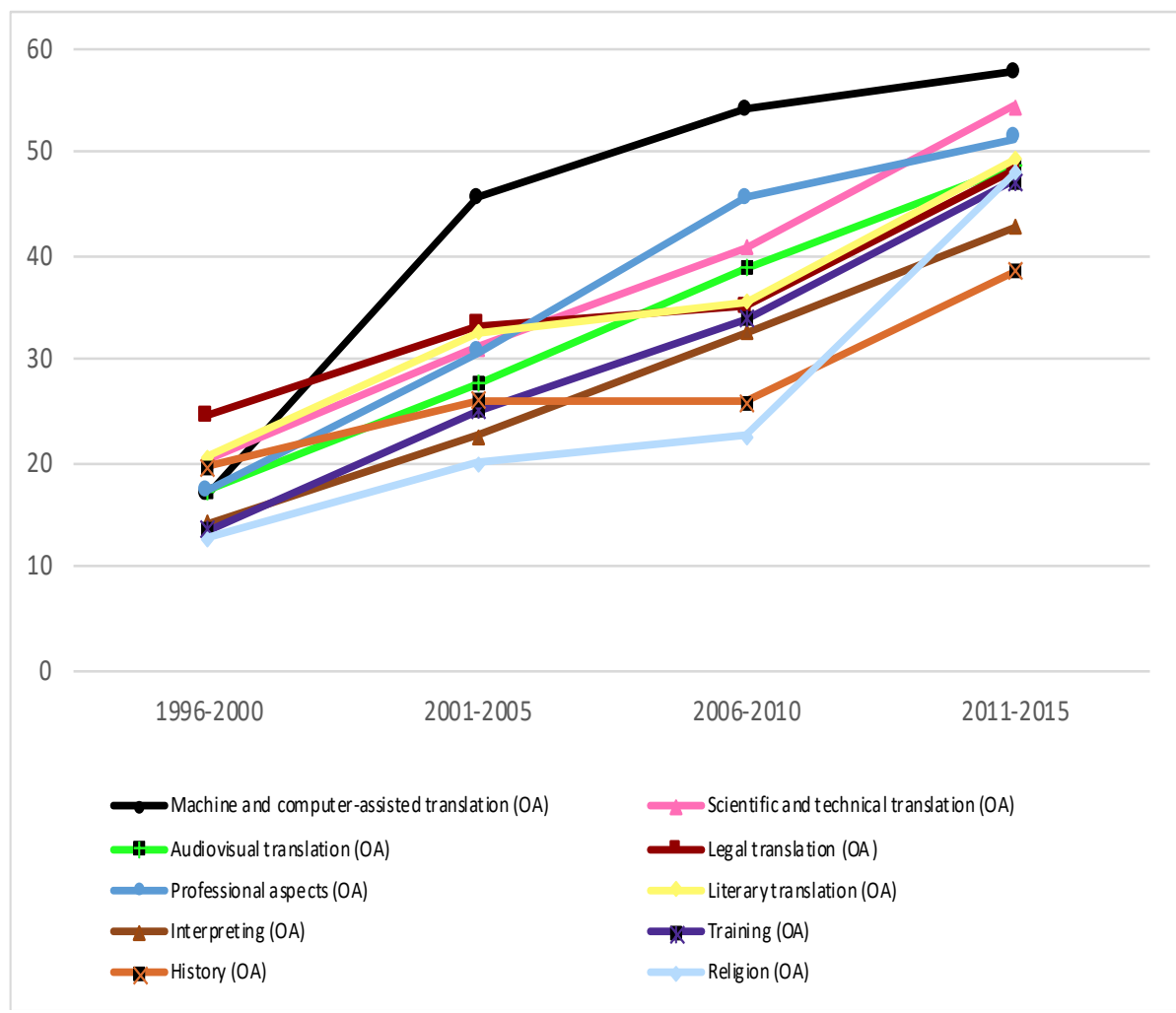

Figure 3. Evolution of access by research topic in percentages (1996-2015)

\subsection{The evolution of access by language}

While the difference between the percentage of OA publications and TA publications is statistically significant for all languages (English: $\chi^{2}[1]=$ 9337.2, $p<0.001, W=0.520$; Spanish: $\chi^{2}[1]=1264.3, p<0.001, W=0.306$; French: $\chi^{2}[1]=644.1, p<0.001, W=0.271$; German: $\chi^{2}[1]=4562.8, p<$ 0.001, $W=0.879$; Portuguese: $\chi^{2}[1]=197.6, p<0.001, W=0.294$; Italian: $\chi^{2}$ $[1]=570.9, p<0.001, W=0.518$; Chinese: $\chi^{2}[1]=692.5, p<0.001, W=$ 0.805; Catalan: $\chi^{2}[1]=6.1, p=0.05, W=0.077$; Galician: $\chi^{2}[1]=9.6, p<$ $0.01, W=0.154$; Polish: $\left.\chi^{2}[1]=79.0, p<0.001, W=0.494\right)$, two groups can be clearly differentiated (Table 4). In the first group (English, Spanish, French, Italian, and Polish) approximately one out of four documents have been published OA. In the second group (Catalan and Galician), the proportion rises to nearly half of the documents. There are some cases that do not fall within these two groups: OA documents in Portuguese amount to 64\%, while OA documents in German and Chinese only represent $6.1 \%$ and $9.7 \%$ respectively.

In the pre-WWW period (1961-1995), the percentage range of documents published OA was very broad but remained less than $20 \%$ for almost all languages, with the exception of French (34.7\%) and Galician (42.9\%). In the WWW period (1996-2015), TA was still the most frequent access type for most languages (English: $\chi^{2}[1]=5172.5, p<0.001, W=0.446$; Spanish: $\chi^{2}$ $[1]=491.7, p<0.001, W=0.211$; French: $\chi^{2}[1]=315.1, p<0.001, W=$ 0.247; German: $\chi^{2}[1]=2339.2, p<0.001, W=0.813$; Italian: $\chi^{2}[1]=260.2$, $p<0.001, W=0.402$; Chinese: $\chi^{2}[1]=506.3, p<0.001, W=0.766$; Polish: $\chi^{2}[1]=47.7, p<0.001, W=0.415$. $)$, except for Portuguese $\left(\chi^{2}[1]=360.0, p\right.$ $<0.001, W=0.426)$ and Galician $\left(\chi^{2}[1]=12.2, p<0.001, W=0.183\right)$, where 
OA was more frequent than TA. In the case of Catalan, there was a balance in terms of the percentages of open-access and toll-access documents $\left(\chi^{2}[1]=\right.$ $2.4, p=0.122, W=0.052$ ).

Table 4. Access by language

\begin{tabular}{|c|c|c|c|c|c|c|}
\hline & \multicolumn{2}{|c|}{ All years } & \multicolumn{2}{|c|}{ 1961-1995 } & \multicolumn{2}{|c|}{$1996-2015$} \\
\hline & OA (\%) & TA (\%) & OA (\%) & TA (\%) & OA (\%) & TA (\%) \\
\hline Portuguese & $\begin{array}{c}64.7 \\
(n=1475)\end{array}$ & $\begin{array}{c}35.3 \\
(n=804)\end{array}$ & $\begin{array}{c}19.9 \\
(n=58)\end{array}$ & $\begin{array}{c}80.1 \\
(n=233)\end{array}$ & $\begin{array}{c}71.3 \\
(n=1417)\end{array}$ & $\begin{array}{c}28.7 \\
(n=571)\end{array}$ \\
\hline Galician & $\begin{array}{c}57.7 \\
(n=232)\end{array}$ & $\begin{array}{c}42.3 \\
(n=170)\end{array}$ & $\begin{array}{c}42.9 \\
(n=15)\end{array}$ & $\begin{array}{c}57.1 \\
(n=20)\end{array}$ & $\begin{array}{c}59.1 \\
(n=217)\end{array}$ & $\begin{array}{c}40.9 \\
(n=150)\end{array}$ \\
\hline Catalan & $\begin{array}{c}46.2 \\
(n=474)\end{array}$ & $\begin{array}{c}53.8 \\
(n=553)\end{array}$ & $\begin{array}{c}5.7 \\
(n=8)\end{array}$ & $\begin{array}{c}94.3 \\
(n=133)\end{array}$ & $\begin{array}{c}52.6 \\
(n=466)\end{array}$ & $\begin{array}{c}47.4 \\
(n=420)\end{array}$ \\
\hline French & $\begin{array}{c}36.5 \\
(n=3201)\end{array}$ & $\begin{array}{c}63.5 \\
(n=5579)\end{array}$ & $\begin{array}{c}34.7 \\
(n=1252)\end{array}$ & $\begin{array}{c}65.3 \\
(n=2353)\end{array}$ & $\begin{array}{c}37.7 \\
(n=1949)\end{array}$ & $\begin{array}{c}62.3 \\
(n=3226)\end{array}$ \\
\hline Spanish & $\begin{array}{c}34.7 \\
(n=4675)\end{array}$ & $\begin{array}{c}65.3 \\
(n=8803)\end{array}$ & $\begin{array}{c}13.4 \\
(n=328)\end{array}$ & $\begin{array}{c}86.6 \\
(n=2128)\end{array}$ & $\begin{array}{c}39.4 \\
(n=4347)\end{array}$ & $\begin{array}{c}60.6 \\
(n=6675)\end{array}$ \\
\hline Polish & $\begin{array}{c}25.3 \\
(n=82)\end{array}$ & $\begin{array}{c}74.7 \\
(n=242)\end{array}$ & $\begin{array}{c}2.1 \\
(n=1)\end{array}$ & $\begin{array}{c}97.9 \\
(n=46)\end{array}$ & $\begin{array}{c}29.2 \\
(n=81)\end{array}$ & $\begin{array}{c}70.5 \\
(n=196)\end{array}$ \\
\hline Italian & $\begin{array}{c}24.1 \\
(n=514)\end{array}$ & $\begin{array}{c}75.9 \\
(n=1617)\end{array}$ & $\begin{array}{c}6.3 \\
(n=33)\end{array}$ & $\begin{array}{c}93.7 \\
(n=489)\end{array}$ & $\begin{array}{c}29.9 \\
(n=481)\end{array}$ & $\begin{array}{c}70.1 \\
(n=1128)\end{array}$ \\
\hline English & $\begin{array}{c}24.0 \\
(n=8300)\end{array}$ & $\begin{array}{c}76.0 \\
(n=26,265)\end{array}$ & $\begin{array}{c}12.8 \\
(n=1091)\end{array}$ & $\begin{array}{c}87.2 \\
(n=7455)\end{array}$ & $\begin{array}{c}27.7 \\
(\mathrm{n}=7209)\end{array}$ & $\begin{array}{c}72.3 \\
(n=18,810)\end{array}$ \\
\hline Chinese & $\begin{array}{c}9.7 \\
(n=104)\end{array}$ & $\begin{array}{c}90.3 \\
(n=964)\end{array}$ & $\begin{array}{c}1.5 \\
(n=3)\end{array}$ & $\begin{array}{c}98.5 \\
(n=202)\end{array}$ & $\begin{array}{c}11.7 \\
(n=101)\end{array}$ & $\begin{array}{c}88.3 \\
(n=762)\end{array}$ \\
\hline German & $\begin{array}{c}6.1 \\
(n=358)\end{array}$ & $\begin{array}{c}93.9 \\
(n=5550)\end{array}$ & $\begin{array}{c}1.2 \\
(n=28)\end{array}$ & $\begin{array}{c}98.8 \\
(n=2344)\end{array}$ & $\begin{array}{c}9.3 \\
(n=330)\end{array}$ & $\begin{array}{c}90.7 \\
(n=3206)\end{array}$ \\
\hline
\end{tabular}

The general picture of language distribution regarding OA is not clearcut and there are some differences which are too significant to be attributable to chance. As a tentative hypothesis, a combination of national traditions/ academic policy and the degree of international presence of a given language seems to overlap here. With regard to the period from 1996 to 2015 there are three broad groups: those around 10\% OA (German and Chinese), those sitting at intermediate level between $29-40 \%$, which broadly corresponds with majority languages in science (English, Spanish, French, Italian and the Polish exception), and a third group comprised of minority languages in science but with a notable presence in TS, with over $50 \%$ OA (Portuguese, Catalan, Galician). The Chinese and German cases are exceptions whose explanation seems to revolve around national traditions and the way they address TS. China seems to be a country where TA science still has a notable plus of prestige that hinders OA journals (interestingly, in this vein, the only TS journal mainly in Chinese classified as OA in BITRA is published in Taiwan). In the German case, $74 \%$ of all TS documents in BITRA in this language are books or book chapters (as opposed to 51\% in BITRA as a whole), and there are only three active TS journals published in German-speaking countries as far as the authors are aware. This preponderance of the less OA-friendly 
formats seems to go a long way towards explaining the German exception. The other two groups are quite homogeneous from a sociolinguistic perspective, with Polish being the only exception. In the case of Polish, there probably could be a higher level of OA, and in fact Poland seems to be rapidly opening up to this publication mode (cf. Kieńć, 2017). The case of the other scientifically peripheral languages (Portuguese, Catalan and Galician) seems to be derived from a need to maximize the dissemination of research results among a limited academic community, combined with the lack of commercial profitability of publishing TA journals in the field of TS, due once again to the shortage of scholars able to read these languages. Public centralized platforms specifically designed for OA, such as the Brazilian Scielo, are also an important support for the OA publication mode.

In the first WWW period (1996-2000), the percentage of publications in OA by language is very ample, ranging from zero to approximately $50 \%$. In the final period (2001-2015), OA publications range from $20 \%$ to nearly $90 \%$. Thus, while the increase has been remarkable for some languages (Portuguese, Catalan, Galician, Italian, and Polish), it was not so for others (German and Chinese). In the middle of these two groups, we found some cases where there has been little change in the percentage of OA publications (English, Spanish, and French). In the cases of Spanish, Galician, Italian, Polish, and German, the increase from the third to the fourth period is more marked than any of the other consecutive periods. Portuguese, Catalan, French, English, and Chinese show the opposite trend: the most pronounced increases are either found between the first and second period, or between the second and third one, or in both. This could be due to an earlier introduction of OA by the publishers working with these languages.

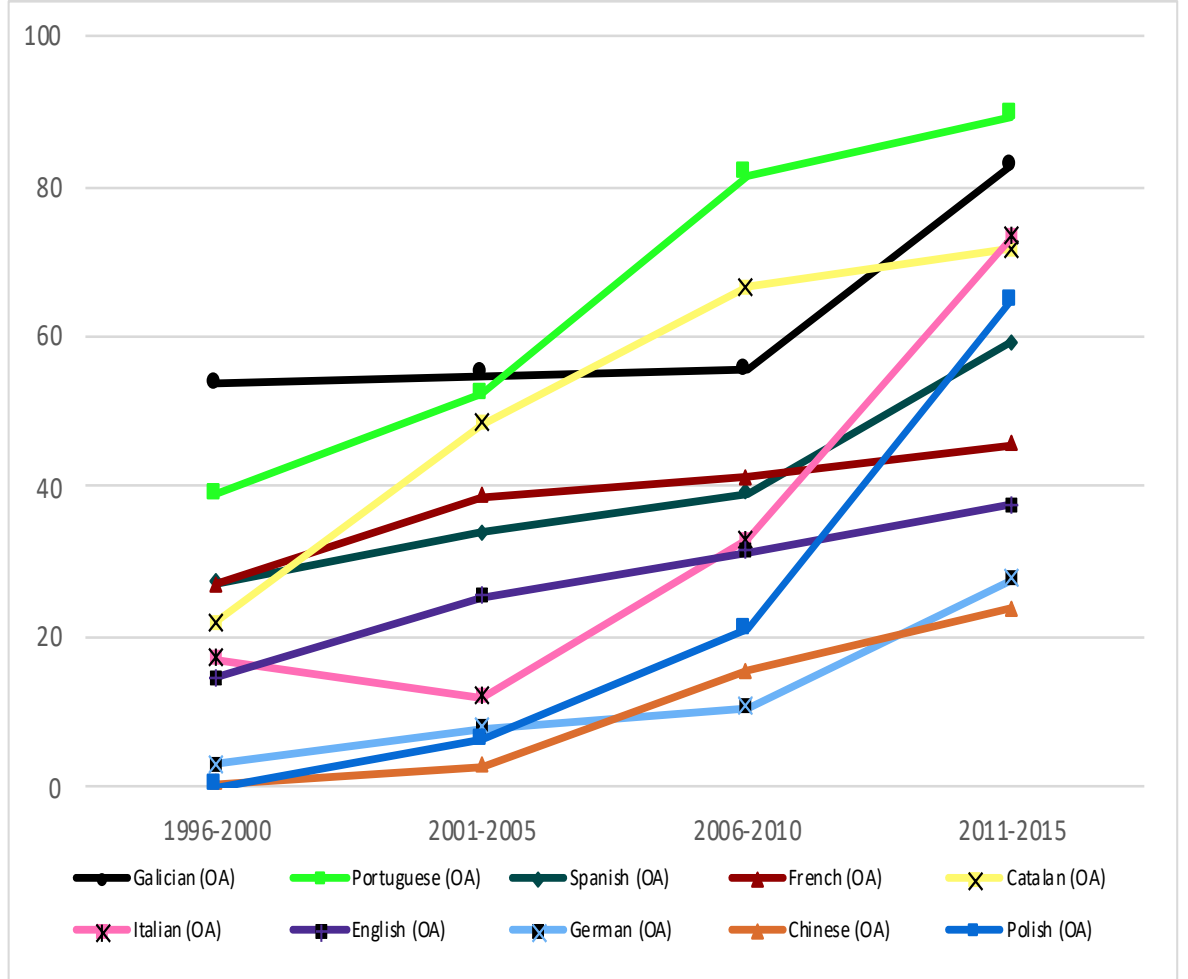

Figure 4. Evolution of access by language in percentages (1996-2015) 


\subsection{The evolution of the online hosting of $\mathrm{OA}$ publications}

All in all, 87.4\% of the OA documents in BITRA from 1961 to 2015 are accessible through non-profit URLs, which are public journal websites, institutional repositories, public publisher websites and personal websites (Table 5). This clearly indicates a tendency in TS toward making OA research accessible free of charge or without needing to register on platforms that might be free in their non-premium mode (such as private repositories) but have commercial ends.

When considering the whole period of analysis (1961-2015), public journal websites host almost half of the existing OA documents, followed by institutional repositories (23\%) and commercial journal websites (20\%). All other options jointly account for $9 \%$ of the documents only.

In the 1961-1995 period, public URLs accounted for $40.2 \%$ of the OA documents, while this doubled to $83.3 \%$ over the $1996-2015$ (83.3\%). There was an abrupt increase of OA journal articles published on public journal websites, accompanied by a decrease in OA journal articles on commercial journal websites. There was also a slight increase in OA both in institutional and private repositories, with a more marked growth of OA on institutional websites.

Table 5. Types of online hosting of OA publications

\begin{tabular}{|c|c|c|c|}
\hline & All years (\%) & $1961-1995(\%)$ & $1996-2015(\%)$ \\
\hline $\begin{array}{l}\text { Public journal } \\
\text { website }\end{array}$ & $\begin{array}{c}47.9 \\
(n=7987)\end{array}$ & $\begin{array}{c}18.0 \\
(n=462)\end{array}$ & $\begin{array}{c}53.3 \\
(n=7525)\end{array}$ \\
\hline $\begin{array}{l}\text { Institutional } \\
\text { repository }\end{array}$ & $\begin{array}{c}23.0 \\
(n=3825)\end{array}$ & $\begin{array}{c}18.1 \\
(n=463)\end{array}$ & $\begin{array}{c}23.8 \\
(\mathrm{n}=3362)\end{array}$ \\
\hline $\begin{array}{l}\text { Commercial } \\
\text { journal website }\end{array}$ & $\begin{array}{c}20.0 \\
(n=3341)\end{array}$ & $\begin{array}{c}58.9 \\
(n=1509)\end{array}$ & $\begin{array}{c}13.0 \\
(n=1832)\end{array}$ \\
\hline $\begin{array}{l}\text { Public publisher } \\
\text { website }\end{array}$ & $\begin{array}{c}4.5 \\
(n=758)\end{array}$ & $\begin{array}{c}2.2 \\
(\mathrm{n}=56)\end{array}$ & $\begin{array}{c}5.0 \\
(\mathrm{n}=702)\end{array}$ \\
\hline Private repository & $\begin{array}{c}2.3 \\
(\mathrm{n}=390)\end{array}$ & $\begin{array}{c}0.5 \\
(n=14)\end{array}$ & $\begin{array}{c}2.7 \\
(\mathrm{n}=376)\end{array}$ \\
\hline Personal website & $\begin{array}{c}1.3 \\
(\mathrm{n}=217)\end{array}$ & $\begin{array}{c}1.9 \\
(\mathrm{n}=48)\end{array}$ & $\begin{array}{c}1.2 \\
(n=169)\end{array}$ \\
\hline $\begin{array}{l}\text { Commercial } \\
\text { publisher website }\end{array}$ & $\begin{array}{c}0.9 \\
(n=146)\end{array}$ & $\begin{array}{c}0.3 \\
(n=8)\end{array}$ & $\begin{array}{c}1.9 \\
(n=138)\end{array}$ \\
\hline
\end{tabular}

OA documents disseminated on public journal websites showed a gradual increase in the period from 1996 to 2015 (Table 6). The opposite trend was observable in the case of OA documents published on commercial journal websites. This is especially remarkable since commercial journals incorporated APCs to enhance open access publishing, but this does not seem to have had the desired effect: the decrease is found both in terms of relative percentages and in absolute terms (from 477 documents in 2006-2010 to 401 documents in 2011-2015).

In the case of institutional repositories, there was an increase in the second five-year period, with almost no changes in the third and fourth periods. The percentage of OA documents published in private repositories 
fluctuated from one period to the next, with a small increase in the fourth period, which was possibly due to the creation of private repositories such as Academia.edu or ResearchGate (both in 2008), which are widely accepted and used in academia. Both public and commercial publisher websites declined over time, reflecting the abovementioned lack of progress affecting the OA publication of books. This same trend applies to individual researchers' websites, which only account for $0.3 \%$ of the OA documents in the 2011-2015 period.

The decrease in OA documents published on personal websites may be due to the fact that both institutional and private repositories allow scholars to create their own profiles and keep their publications together, while these are also placed on much more visited and visible sites than exclusively personal websites could ever be. Another explanation of this trend favouring private repositories might be that they tend to allow uploading documents without any previous check of licenses and copyright issues, whereas librarians in charge of institutional repositories exert a tight control in this regard. Therefore, scholars find it more friendly and straightforward to share their publications in private repositories. Moreover, maintaining one's own personal website tends to be more time-consuming than just uploading or sending a paper to a repository, where other people perform this task on behalf of the researcher.

Table 6. Evolution of types of online hosting of OA publications

\begin{tabular}{|c|c|c|c|c|}
\hline & $\begin{array}{c}1996-2000 \\
(\%)\end{array}$ & $\begin{array}{c}2001-2005 \\
(\%)\end{array}$ & $\begin{array}{c}2006-2010 \\
(\%)\end{array}$ & $\begin{array}{c}2011-2015 \\
(\%)\end{array}$ \\
\hline $\begin{array}{l}\text { Public journal } \\
\text { website }\end{array}$ & $\begin{array}{c}38.6 \\
(n=713)\end{array}$ & $\begin{array}{c}44.7 \\
(n=1400)\end{array}$ & $\begin{array}{c}57.2 \\
(n=2493)\end{array}$ & $\begin{array}{c}61.1 \\
(n=2919)\end{array}$ \\
\hline $\begin{array}{l}\text { Commercial } \\
\text { journal website }\end{array}$ & $\begin{array}{c}21.9 \\
(n=406)\end{array}$ & $\begin{array}{c}17.5 \\
(n=548)\end{array}$ & $\begin{array}{c}11.0 \\
(n=477)\end{array}$ & $\begin{array}{c}8.4 \\
(n=401)\end{array}$ \\
\hline $\begin{array}{l}\text { Institutional } \\
\text { repository }\end{array}$ & $\begin{array}{c}19.5 \\
(n=384)\end{array}$ & $\begin{array}{c}24.7 \\
(n=774)\end{array}$ & $\begin{array}{c}23.6 \\
(n=1028)\end{array}$ & $\begin{array}{c}24.6 \\
(n=1176)\end{array}$ \\
\hline $\begin{array}{l}\text { Public publisher } \\
\text { website }\end{array}$ & $\begin{array}{c}9.3 \\
(n=236)\end{array}$ & $\begin{array}{c}4.2 \\
(n=132)\end{array}$ & $\begin{array}{c}5.2 \\
(n=225)\end{array}$ & $\begin{array}{c}2.3 \\
(n=109)\end{array}$ \\
\hline $\begin{array}{l}\text { Commercial } \\
\text { publisher } \\
\text { website }\end{array}$ & $\begin{array}{c}5.8 \\
(n=14)\end{array}$ & $\begin{array}{c}2.2 \\
(n=69)\end{array}$ & $\begin{array}{c}0.8 \\
(n=34)\end{array}$ & $\begin{array}{c}0.4 \\
(n=21)\end{array}$ \\
\hline $\begin{array}{l}\text { Personal } \\
\text { website }\end{array}$ & $\begin{array}{c}3.3 \\
(n=60)\end{array}$ & $\begin{array}{c}1.8 \\
(n=57)\end{array}$ & $\begin{array}{c}0.8 \\
(n=36)\end{array}$ & $\begin{array}{c}0.3 \\
(n=16)\end{array}$ \\
\hline $\begin{array}{l}\text { Private } \\
\text { repository }\end{array}$ & $\begin{array}{c}1.6 \\
(n=29)\end{array}$ & $\begin{array}{c}4.8 \\
(n=151)\end{array}$ & $\begin{array}{c}1.4 \\
(n=62)\end{array}$ & $\begin{array}{c}2.8 \\
(n=134)\end{array}$ \\
\hline
\end{tabular}

\subsection{The evolution of access to active TS journals depending on the type of publisher}

In this regard, it might also be interesting to specifically analyse TS active journals as an especially relevant reflection of how OA and TA have developed within the discipline. For a journal to be considered as TS in BITRA, at least $50 \%$ of its contents must directly deal with translation or interpreting. Table 7 presents the distribution of active TS journals published in OA and TA by public and commercial publishers. As expected, public TS publishers tend to publish OA journals more frequently than TA journals $\left(\chi^{2}\right.$ $[1]=7.8, p<0.01, W=0.211)$, whereas commercial TS publishers tend to 
publish TA journals more frequently than OA journals $\left(\chi^{2}[1]=11.1, p<\right.$ $0.001, W=0.556)$. The same tendencies are observed in the WWW period (1996-2015): TS public publishers tend to publish OA journals $\left(\chi^{2}[1]=12.3\right.$, $p<0.001, W=0.273)$, while commercial publishers tend to publish TA journals $\left(\chi^{2}[1]=11.1, p<0.001, W=0.556\right)$.

Table 7. Access to active journals depending on the type of journal publisher (public vs. commercial)

\begin{tabular}{lcccccc}
\hline & \multicolumn{2}{c}{ All years } & \multicolumn{2}{c}{$1961-1995$} & \multicolumn{2}{c}{$1996-2015$} \\
\cline { 2 - 7 } & OA (\%) & TA (\%) & OA (\%) & TA (\%) & OA (\%) & TA (\%) \\
\hline Public & 60.6 & 39.4 & 36.6 & 63.4 & 63.6 & 36.4 \\
& $(\mathrm{n}=106)$ & $(\mathrm{n}=69)$ & $(\mathrm{n}=23)$ & $(\mathrm{n}=40)$ & $(\mathrm{n}=105)$ & $(\mathrm{n}=60)$ \\
Commercial & 22.2 & 77.8 & 14.3 & 85.7 & 22.2 & 77.8 \\
& $(\mathrm{n}=8)$ & $(\mathrm{n}=28)$ & $(\mathrm{n}=2)$ & $(\mathrm{n}=12)$ & $(\mathrm{n}=8)$ & $(\mathrm{n}=28)$ \\
\hline
\end{tabular}

While the percentage of TS journals published in OA by public publishers increases over time, this does not apply in the case of commercial publishers that publish OA TS journals, since there the percentage is stable from the first (1996-2000) to the second period (2001-2005), before reducing markedly in the third period (2006-2010) and slightly rising in the fourth one (2011-2015) (Figure 5). The difference between public and commercial publishers regarding the access type of this kind of journals has grown more marked over time with a generalized change of TA into OA in the case of existing public journals and a preference for OA in the case of new and emerging journals.

There are two noteworthy conclusions to be drawn from this analysis. Firstly, the systematicity with which older public journals have migrated to $\mathrm{OA}$, or with which new journals have elected this mode since their inception (cf. the illuminating example of Spanish TS journals in 4.2.) A majority of OA was to be expected in the case of public journals, but -with the exception of very few countries such as China- the move to OA could be termed a veritable landslide. This implies a turning point for this kind of access in active journals, which currently comprise public journals in almost $80 \%$ of the cases in the field of TS. Secondly, as explained above, the stagnation or reduction of OA within very modest ratios in commercial journals seems to indicate that, in TS at least, the APC model is so far not working if indeed the intention was to use it in order to integrate commercial journals into the OA movement.

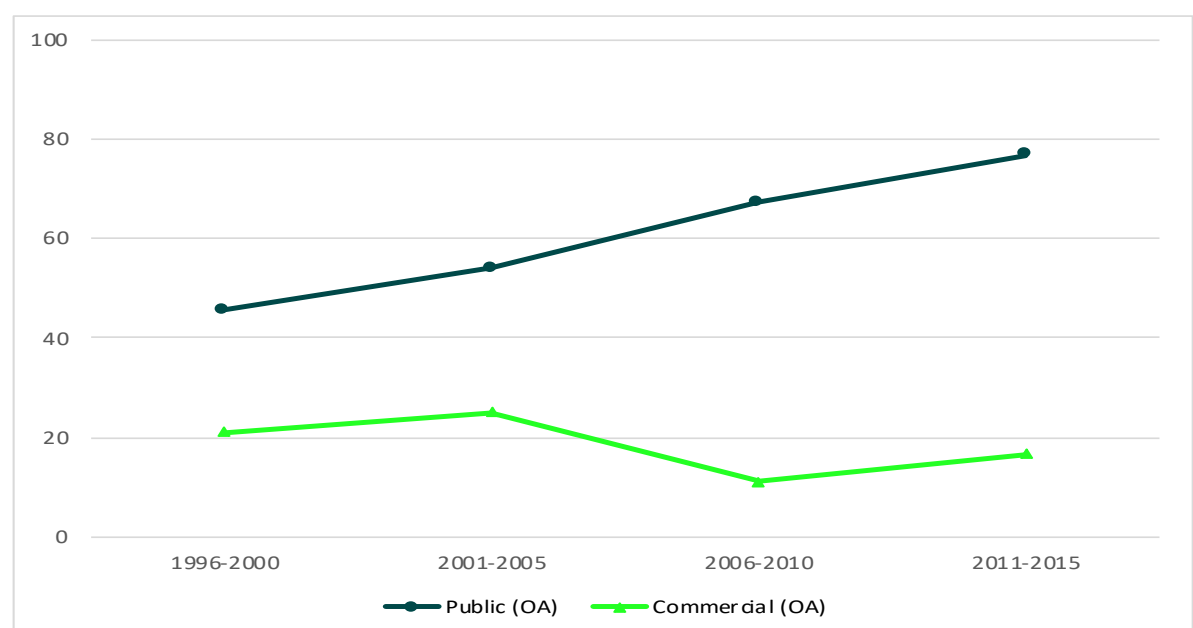

Figure 5. Ratios for the evolution of access type to active TS journals by nature of the publisher (1996-2015) 


\subsection{Factors that currently (2011-2015) predict open access}

A binomial logistic regression analysis was performed to determine which factors predict OA in the 2011-2015 period successively based on the format (journal article, book chapter, book, journal special issue, or $\mathrm{PhD}$ thesis), the research topic (literary translation, training, history, scientific and technical translation, interpreting, professional issues, machine and computer-assisted translation, audiovisual translation, religion and legal translation), and the language (English, Spanish, French, German, Portuguese, Italian, Chinese, Catalan, Galician, and Polish).

The logistic regression model was statistically significant $\left(\chi^{2}[8]=167.7\right.$, $p<0.001$ ). The model explained $49.8 \%$ (Nagelkerke $\mathrm{R}^{2}$ ) of the variance in OA and correctly classified $77.7 \%$ of cases. Table 8 classifies the odds ratio of the factors included in the regression equation in two groups: factors predicting $\mathrm{OA}$ and factors predicting $\mathrm{TA}$.

Table 8. Factors predicting open access

\section{Factors}

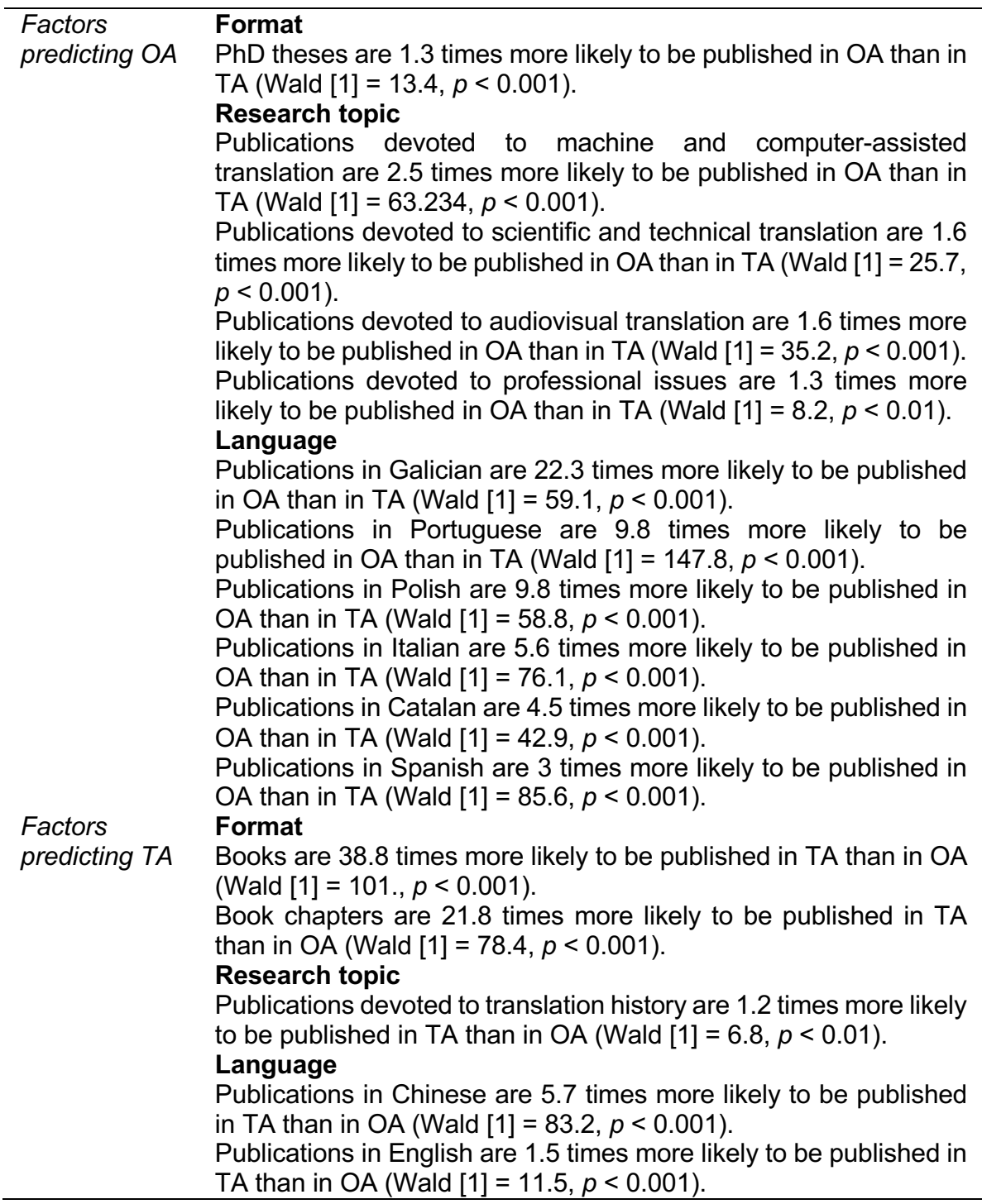
Format: articles (Wald $[1]=0.1, p=0.815$ ) and journal special issues (Wald [1] $=0.1$, $p=0.815)$ do not predict OA nor TA. Research topic: publications devoted to didactics 
(Wald $[1]=1.3, p=0.251$ ), religion (Wald $[1]=0.001, p=0.970$ ), literary translation (Wald $[1]=0.01, p=0.908$ ), interpreting (Wald $[1]=0.08, p=0.777$ ) and legal translation (Wald $[1]=0.261, p=0.609$ ) do not predict OA nor TA. Language: Publications in French (Wald [1] $=0.2, p=0.645$ ) and in German (Wald [1] $=1.8, p$ $=0.183)$ do not predict $\mathrm{OA}$ nor TA.

\section{Conclusions}

Regarding our two first research questions, we can start by stating that the evolution of Open Access has been remarkable in TS, with a sustained growth from $18.0 \%$ in $1996-2000$ to $46.6 \%$ in $2011-2015$, almost reaching a balance with toll-access publication. Figure 1 on the diachrony of OA vs TA (19962015 ) is probably one of those pictures worth a thousand words, and it speaks for itself.

As to the bibliometric factors that exert a significant influence on the decision or the mere possibility of OA or TA publishing, there are some interesting points to make here.

Public journals specializing in TS perhaps reflect this development most dramatically, reaching almost $80 \%$ of OA publications in 2011-2015. At the same time, there are niches where OA clearly lags behind, such as the book format, and certain countries - such as China - which show signs of resistance against this trend. There are a number of reasons which may partly explain the marked difference between journals and books. The first one is financial, since books are still published almost always in print. The second reason relates to academic management, since journals tend to be responsibility of university departments, whereas books tend to fall into the hands of centralized publishing services. A third reason might be prestige, since subscription and payment are still generally considered to contribute added value in many parts of the world. PhD theses, for their part, might be taken as a sign of the institutional commitment to open science, since it is the universities that promote this access mode, which involves almost no cost, with a growth from under $22 \%$ of OA in $1996-2000$ to $77 \%$ in $2011-2015$.

Thematically, there do not seem to be very marked correlations between topic of study and publication access mode, with a slight trend for machinetranslation and specialized issues to be more likely published OA. Language distribution of OA, finally, does not show clear-cut patterns, indicating that a combination of cultural traditions and the degree of internationalization of each language results in various attitudes towards this issue.

Regarding our fourth research objective, we have quantified the degree to which these variables act as predictors of OA or TA, providing a detailed list of how these bibliometric factors apply to the publication mode.

Finally, our fifth research question about the kind of URLs hosting OA publications dealing with TS reveals that public institutions are by far the main online spaces where this mode of publication is found. Currently, open access in TS is a very generalized practice among public actors, and this is increasingly so, passing from $75.5 \%$ of OA by non-commercial publishers in 1996-2000 to the current $88.4 \%$. This has brought about the inverse process in commercial publishers, whose OA productivity has been more than halved, from $24.5 \%$ in $1996-2000$ to $11.6 \%$ in $2011-2015$. This seems to indicate that the attempt to embark on the open-science movement through the articleprocessing-charges (APCs) method proposed by many commercial journals is not working for the moment, if their intention is to provide generalized free access to science. Possibly, the cost of APCs is still too high for many 
researchers, who increasingly publish preprints or other versions of their contributions on all kinds of OA repositories to overcome this barrier.

All in all, after a sustained growth which is still ongoing, open access seems to be reaching a turning point whose final dimensions are still to be seen. The data we have analysed seem to clearly indicate that open access is here to stay, with non-profit actors featuring a very strong commitment towards it, and commercial publishers lagging far behind. Perhaps a notable reduction of APCs might change this trend.

The present study has presented a first critical analysis of the presence and evolution of open access in TS. In our next study on this same topic, we will analyse the impact (measured in number of citations) of OA publications devoted to TS and we will compare it to that of TA publications in order to test the general hypothesis (Kurtz \& Brody, 2006, p. 1; Li et al., 2018, p. 3) that $\mathrm{OA}$ involves a citation advantage.

\section{Acknowledgement}

This research has been partially funded by the Departament de Traducció, d'Interpretació i d'Estudis de l'Àsia Oriental (Universitat Autònoma de Barcelona).

\section{References}

Archambault, É., Amyot, D., Deschamps, P., Nicol, A., Provencher, F., Rebout, L., $\&$ Roberge, G. (2014). Proportion of open access papers published in peerreviewed journals at the European and world levels-1996-2013. European Commission.

Biblioteca d'Humanitats. Universitat Autònoma de Barcelona (2019). RETI: Revistes dels estudis de traducció i interpretació: Indicadors de qualitat. [Quality indicators for TS Journals]. Retrieved from http://www.uab.cat/libraries/reti

Björk, B. C. (2016). The open access movement at a crossroad: Are the big publishers and academic social media taking over? Learned Publishing 29(2), 131-34. http://doi.org/10.1002/leap.1021

Chan, L., Cuplinskas, D., Eisen, M., Friend, F., Genova, Y., Guédon, J-C., Hagemann, M., Harnad, S., Johnson, R., Kupryte, R., La Manna, M., Rév, I., Segbert, M., de Souza, S. Suber, P., \& Velterop, J. (2002). Budapest open access initiative. https://www.budapestopenaccessinitiative.org/read

Desblache, L. (2012). Mapping digital publishing for all in translation. In A. Remael, P. Orero, \& M. Carroll (Eds.), Audiovisual translation and media accessibility at the crossroads. Media for all 3 (pp. 85-108). Amsterdam: Rodopi.

European Science Foundation (2020). https://www.coalition-s.org/about/

Franco Aixelá, J. (2001-2019). BITRA (Bibliography of Interpreting and Translation). Open-access database. http://doi.org/10.14198/bitra

Franco Aixelá, J. (2012). A critical overview of the Translation Studies journals published in Spain. In I. García-Izquierdo, \& E. Monzó (Eds.), Iberian studies on translation and interpreting (pp. 339-61). Oxford, Bern, Bern, Berlin, Bruxelles, Frankfurt am Main, New York, Wien: Peter Lang.

García González, Marta, \& Peter Sandrini (2015). Translation and openness: An introduction. Translation and Openness. Insbruck: Insbruck University Press. https://doi.org/10.15203/2936-88-2-1

Giménez Toledo, E. (2018). La financiación de libros académicos en acceso abierto [The funding of scholarly open access books]. In E. Giménez Toledo, \& J. F. Córdoba Restrepo (Eds.), Edición académica y difusión. Libro abierto en 
Iberoamérica (pp. 17-27). Bogotá \& Granada: Editorial Universidad del Rosario \& Editorial Comares.

Green, T. (2017). We've failed: Pirate black open access is trumping green and gold and we must change our approach. Learned Publishing, 30(4), 325-29. http://doi.org/10.1002/leap.1116

Kieńć, W. (2017). Authors from the periphery countries choose open access more often. Learned Publishing, 30(2), 125-31. http://doi.org/10.1002/leap.1093

Kurtz, M., \& Brody. T. 2006. The impact loss to authors and research. In N. Jacobs (Ed.), Open access: Key strategic, technical and economic aspects. Oxford: Chandos.

Li, Y., Wu, C., Yan, E., \& Li, K. (2018). Will open access increase journal CiteScores? An empirical investigation over multiple disciplines. PLOS ONE 13(8), 1-21. https://doi.org/10.1371/journal.pone.0201885

Melero, R., Laakso, M, \& Navas-Fernández, M. (2017). Openness of Spanish scholarly journals as measured by access and rights. Learned Publishing, 30(2), 143-55. http://doi.org/10.1002/leap.1095

Pardo, A., \& Ruiz, M.A. (2012). Análisis de datos en ciencias sociales y de la salud III. Madrid: Editorial Síntesis.

Swan, A. (2012). Policy guidelines for the development and promotion of open access. UNESCO: Paris.

UNESCO (2015). Concepts of openness and open access. Open access for researchers. Paris.

van Leeuwen, T. N., Tatum, C., \& Wouters, P. F. (2018). Exploring possibilities to use bibliometric data to monitor gold open access publishing at the national level. Journal of the Association for Information Science and Technology, 69(9), 1161-73. http://doi.org/10.1002/asi.24029 